\title{
A modified bite block for fibreoptic bronchoscopy in patients with face and neck scars
}

\author{
Fu S. Xue, MD • Hai T. Sun, MD • Ya C. Xu, MD • \\ Xu Liao, MD · Jian H. Liu, MD
}

Received: 2 May 2011/ Accepted: 1 June 2011/Published online: 11 June 2011

(C) Canadian Anesthesiologists' Society 2011

\section{To the Editor,}

Awake fibreoptic intubation is often considered to be the "gold standard" method of difficult airway management. ${ }^{1}$ However, a common concern when using the oral route is damage to the fibreoptic bronchoscope (FOB) due to biting. Also, passing the FOB in the midline is pivotal for successful fibroscopy. ${ }^{2}$ Although special intubating airway devices are designed to solve these issues, they are difficult to insert in awake patients with a severely limited mouth opening. In burn patients, head and neck movements are also limited by scar contractures, and these airway devices can occasionally make fibroscopy difficult because their distal opening may move from the glottis or even face the posterior pharyngeal wall. ${ }^{3}$ During the past seven years, we have attempted to use a modified bite block as a substitute for the special intubating airways during awake fibreoptic orotracheal intubation in patients with an airway made difficult because of face and neck scar tissue.

We used a disposable hollow bite block (Sujia Medical instrument Co., Ltd, Zhejing, China) $6 \mathrm{~cm}$ in length to protect the orotracheal tube from being bitten by the

Fu S. Xue and Hai T. Sun-contributed equally to this work.

F. S. Xue, MD $(\bowtie)$ · Y. C. Xu, MD · X. Liao, MD .

J. H. Liu, MD

Department of Anesthesiology, Plastic Surgery Hospital, Chinese Academy of Medical Sciences and Peking Union Medical College, 33 Ba-Da-Chu Road, Shi-Jing-Shan District, Beijing 100144, People's Republic of China

e-mail: fruitxue@yahoo.com.cn

H. T. Sun, MD

Cancer Hospital, Chinese Academy of Medical Sciences and Peking Union Medical College, Beijing, People's Republic of China patient. On the two sides, there are flat grooves to place the endotracheal tube (ETT) (Figure A). The maximal outer diameter of the bite block is $12 \mathrm{~mm}$, and its inner lumen can accommodate a cuffed ETT up to $7.5 \mathrm{~mm}$ in inner diameter (Figure B). Before use, one side of the bite block is cut longitudinally in the midline with scissors (Figure C), which facilitates removal after intubation.

Typically, fentanyl $1.5 \mu \mathrm{g} \cdot \mathrm{kg}^{-1} i v$ and increments of midazolam (up to $4 \mathrm{mg} i v$ ) are administered to establish the desired level of sedation. ${ }^{4}$ If possible, airway anesthesia is performed with a translaryngeal injection of $2 \%$ lidocaine. The modified bite block is placed between the patient's central incisors to accommodate the FOB, which is inserted as the $2 \%$ lidocaine is sprayed as described previously (Figure D). ${ }^{5}$ Next, the ETT is advanced over the FOB into the trachea with a slight rotating motion (Figure E). Following intubation, the bite block is disengaged from the ETT by opening the block's incised side (Figure F).

After local ethics committee approval and written informed consent, we used this technique in 23 adult patients (14 men) who were undergoing repair surgeries of face and head scars under general anesthesia. The patients' ages ranged from 19-57 yr. They all displayed limited mouth opening because of face scars (interincisor distance: 11-28 $\mathrm{mm}$ ), and they were not fit for nasotracheal intubation because of nostril abnormities or surgical considerations. Sixteen of these patients also showed limited head and neck movement due to their scars. A translaryngeal injection was performed in five patients, and airway topical anesthesia was achieved in the remaining patients through the FOB. Awake fibreoptic intubation was completed successfully at the first (19 patients) or second attempt (four cases). The time required for airway management, defined as the period from the first application of lidocaine to completion of tracheal intubation, was $10.4(6.8) \mathrm{min}$ [range 6.7-19.2 $\mathrm{min}$ ]. 

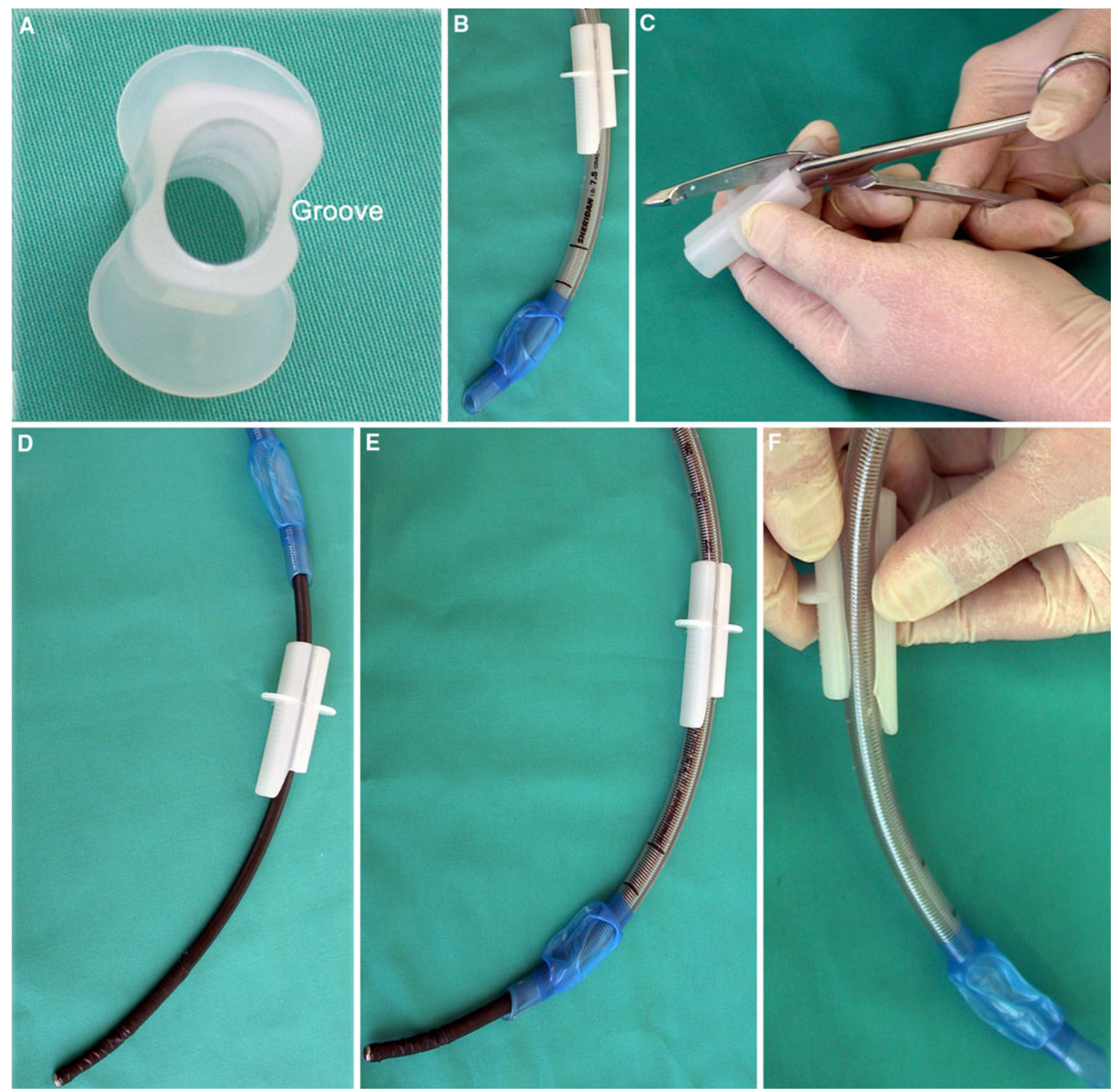

Figure A) The disposable hollow bite block, $6 \mathrm{~cm}$ long with a maximum outer diameter of $12 \mathrm{~mm}$. B) The inner lumen of the bite block can accommodate a cuffed endotracheal tube up to $7.5 \mathrm{~mm}$ in inner diameter. C) One side of the bite block is split longitudinally in the middle using scissors. D) A fibreoptic bronchoscope, which is loaded with a size $7.5 \mathrm{~mm}$ wire-reinforced tube, is inserted. E) The endotracheal tube is advanced over the fibreoptic bronchoscope via the modified bite block. F) The modified bite block is disengaged from the endotracheal tube after intubation
Although the patients were observed to close their mouths involuntarily, no FOB damage from biting occurred.

This preliminary experience suggests that this modified bite block is helpful when performing awake fibreoptic orotracheal intubation in patients with a limited mouth opening and/or limited head and neck movements due to scar tissue. During fibreoptic bronchoscopy, it can prevent
FOB damage by protecting it from being bitten by the awake patient, and the block can hold the FOB at the midpoint of the patient's mouth to facilitate exposure of the glottis. ${ }^{2}$ Additionally, the ETT can be inserted smoothly through this modified device over the FOB and into the trachea.

Competing interests None declared. 


\section{References}

1. American Society of Anesthesiologists Task Force on Management of the Difficult Airway. Practice guidelines for management of the difficult airway: an updated report by the American Society of Anesthesiologists Task Force on Management of the Difficult Airway. Anesthesiology 2003; 98: 1269-77.

2. Wheeler M, Ovassapian A. Fiberoscopy-endoscopy aided technique. In: Hagberg CA, editor. Benumof's Airway Management: Principles and Practice. 2nd ed. St. Louis, MO: Mosby-Year Book Inc; 2007. p. 405-26.
3. Xue F, An $G, X u K$, Deng $X$, Tong $S, L i G$. The summarization of clinical experience of difficult tracheal intubation (Chinese). Zhongguo Yi Xue Ke Xue Yuan Xue Bao 2000; 22: 170-3.

4. He $N$, Хиe $F S, X u Y C$, Liao $X, X u X Z$. Awake orotracheal intubation under airway topical anesthesia using the Bonfils in patients with a predicted difficult airway. Can J Anesth 2008; 55 : 881-2.

5. Хиe FS, Liu HP, He N, et al. Spray-as-you-go airway anesthesia in patients with a difficult airway: a randomized, double-blind comparison of $2 \%$ and $4 \%$ lidocaine. Anesth Analg 2009; 108: 536-43. 